\title{
PROTEINOGRAMA DO LIQUIDO CEFALORRAQUEANO EM AFECÇÕES DEGENERATIVAS DO SISTEMA NERVOSO CENTRAL
}

\author{
A. SpINA-FranÇa *
}

Entre as afecções degenerativas de sistema nervoso central (SNC) são incluidos processos de etiologia heterogênea, muitas vêzes obscura. Dessa forma, é difícil classificá-las satisfatòriamente, sendo, também, mal estabelecidos os limites de separação entre essas afecções e as de grupos nosológicos próximos.

Estudos bioquímicos vêm trazendo novos conhecimentos quanto à natureza de algumas dessas afecções. Green ${ }^{3}$, em revisão feita em 1958, salienta diversas contribuições com o estudo bioquímico do líquido cefalorraqueano (LCR). Em certas doenças degenerativas do SNC, especialmente naquelas em que há comprometimento cerebral, pode haver aumento de globulina $\beta$ no LCR. Esser ${ }^{1}$ foi dos primeiros a chamar a atenção para êsse fato, ulteriormente confirmado por vários pesquisadores ${ }^{5}$.

Neste trabalho são apresentadas as observações sôbre o proteinograma do LCR de pacientes com afecções degenerativas do SNC. A finalidade do estudo é chamar a atenção para as alterações do conteúdo de $\beta$-globulina no LCR nesse tipo de afecções e avaliar o provável papel desempenhado por ela nas alterações metabólicas ocasionadas pela doença.

\section{MATERIAL E MÉTODOS}

Foi estudado o proteinograma do LCR de 28 pacientes com afeções degenerativas do sistema nervoso central. O diagnóstico provável do tipo de afecção e o registro dos pacientes são referidos no quadro 1.

Para cada caso foi feito o proteinograma de uma amostra de LCR. Em dois pacientes (casos 13 e 15) o exame foi repetido cêrca de um e três anos depois.

As amostras analisadas eram normais quanto às proprledades físicas e citologia, sendo negativas as reações de fixação do complemento para sífilis e para cisticercose.

A taxa de proteínas totais foi calculada pelo método turbidimétrico do ácido tricloracético e o estudo das fracōes protêicas foi feito por eletroforese em papel. As técnicas empregadas foram referidas anteriormente ", bem como os valôres normais respectivos ${ }^{\top}$.

\section{RESULTADOS}

Os resultados obtidos são apresentados no quadro 1 .

A concentração protêica total das amostras de LCR estudadas era normal em todos os casos, com exceção de dois (casos 17 e 22). Estes pacientes apresentavam degeneração hepatolenticular.

Trabalho da Clinica Neurológica da Fac. Med. da Univ. de São Paulo (Prof. Adherbal Tolosa): *Assistente. 
A alteraçāo mais freqüentemente observada no perfil protêico do LCR dos casos estudados se refere ao percentual da $\beta$-globulina. O teor dessa globulina estava aumentado em 12 pacientes $(\operatorname{casos} 6,8,13,14,15,18,20,22,23,24,26$ e 28). O aumento de $\beta$-globulina era acompanhado de diminuição do teor de albumina em 6 pacientes (casos 6, 14, 15, 20, 22 e 23), de $\alpha$-globulinas em um (caso 18) e de $\gamma$-globulina em outro (caso 24). Em um paciente (caso 20) havia também aumento discreto de $\gamma$-globulina. No caso 1 ocorreu discreto aumento isolado de $\gamma$-globulina.

No caso 13, o segundo exame, feito cêrca de um ano depois do primeiro, foi normal. No caso 15, o segundo exame, feito cêrca de três anos depois, mostrou alterações semelhantes às encontradas no primeiro exame.

\begin{tabular}{|c|c|c|c|c|c|c|c|c|c|}
\hline \multirow[t]{4}{*}{ Caso } & \multirow[t]{4}{*}{ Reg. } & \multirow[t]{4}{*}{ Diagnóstico } & \multicolumn{7}{|c|}{$L C R$} \\
\hline & & & \multirow[t]{3}{*}{$P . T$. } & \multicolumn{6}{|c|}{ Fracões $(\%)$} \\
\hline & & & & \multirow[t]{2}{*}{$P A$} & \multirow[t]{2}{*}{$\Lambda$} & \multicolumn{4}{|c|}{ Globulinas } \\
\hline & & & & & & $\alpha_{1}$ & $a_{2}$ & $\beta$ & $\gamma$ \\
\hline 1 & 382 & Esclerose lateral & 30 & 5,0 & 44 & 4,4 & 6,6 & 27 & 13,0 \\
\hline 2 & 1225 & amiotrófica & 25 & 1,0 & 55 & 3,0 & 7,0 & 20 & 14.0 \\
\hline 3 & 271 & Doença de Friedreich & 22 & 2,0 & 47 & 4,5 & 9,5 & 22 & 15,0 \\
\hline 4 & 1036 & & 17 & 2,0 & 51 & 5,0 & 7,0 & 25 & 10,0 \\
\hline 5 & 1046 & & 28 & 1,0 & 47 & 7,0 & 7,0 & 27 & 11,0 \\
\hline 6 & 1044 & & 28 & 2,0 & 37 & 6,0 & 11,0 & 30 & 14,0 \\
\hline 7 & 780 & Heredo-degeneraç̃o & 26 & 1,0 & 56 & 4,7 & 6,3 & 23 & 9,0 \\
\hline 8 & 770 & espino-cerebelar & 28 & 1,0 & 45 & 4,5 & 8,5 & 28 & 13,0 \\
\hline 9 & 311 & de Pierre-Marie & 17 & 1,0 & 51 & 7,0 & 10,0 & 20 & 11,0 \\
\hline 10 & 1295 & & 26 & 5,6 & 50 & 5,1 & 8,3 & 20 & 11,0 \\
\hline 11 & 1151 & Degeneração olivo- & 11 & 2,5 & 56 & 4,5 & 6,5 & 22 & 8,5 \\
\hline 12 & 811 & ponto-cerebelar & 25 & 0,5 & $5 \mathrm{C}$ & 4,0 & 10,0 & 27 & 8,5 \\
\hline 13 & 477 & & 18 & 1,3 & 45 & 4,0 & 6,7 & 31 & 12,0 \\
\hline 14 & 651 & Atrofia cerebelar & 15 & 1,0 & 42 & 5,5 & 5,5 & 32 & 14,0 \\
\hline 15 & 683 & & 24 & 1,0 & 40 & 3,0 & 5,0 & 39 & 12,0 \\
\hline 16 & 670 & Degeneração & 27 & 0,5 & 59 & 5,0 & 5,5 & 22 & 8,0 \\
\hline 17 & 149 & hépato-lenticular & 35 & 2,5 & 52 & 6,5 & 10,0 & 20 & 10,0 \\
\hline 18 & 1011 & & 16 & 6,1 & 44 & 2,7 & 3,2 & 30 & 14,0 \\
\hline 19 & 1025 & & 22 & 0,0 & 60 & 3,0 & 7,4 & 20 & 9,6 \\
\hline 20 & 1133 & & 17 & 3,5 & 42 & 4,0 & 6,5 & 29 & 15,0 \\
\hline 21 & 574 & & 19 & 5,0 & 49 & 6,5 & 6,5 & 22 & 11,0 \\
\hline 22 & 1048 & & 53 & 0,0 & 39 & 4,0 & 7,0 & 37 & 13,0 \\
\hline 23 & 899 & Degeneração & 17 & 6,0 & 42 & 4,5 & 7,0 & 32 & 8,5 \\
\hline 24 & 908 & cérebro-macular & 19 & 1,5 & 54 & 4,0 & 5,0 & 30 & 5,5 \\
\hline 25 & 29 & & 15 & 1,0 & 54 & 5,0 & 6,0 & 24 & 10,0 \\
\hline 26 & 1097 & Doença de Pick & 22 & 1,0 & 48 & $\mathbf{5 , 0}$ & 8,0 & 28 & 10,0 \\
\hline 27 & 1419 & Encefalopatia & 22 & 1,2 & 56 & 5,9 & 5,9 & 20 & 11,0 \\
\hline 28 & 1418 & heredo-degenerativa & 14 & 0,0 & 52 & 3,7 & 7,3 & 28 & 9,0 \\
\hline
\end{tabular}

Quadro 1 - Registro $e$ diagnóstico dos casos estudados e o resultado do proteinograma do LCR. Para cada caso é referida a concentração protêica total (P.T.) em $m g / 100 \mathrm{ml} e$ o percentual das fraçöes protêicas: pré-albumina $(P A)$, albumina $(A)$ e globulinas $\alpha_{1}, a_{2}, \beta$ e $\gamma$. Os teores da fracio $\tau$ foram reunidos aos de $\beta$-globulina. 


\section{COMENTARIOS}

Os dados apresentados comprovam mais uma vez que a ocorrência de hiperproteinorraquia em afecções de tipo degenerativo do SNC não é comum. Apenas em dois pacientes portadores de degeneração hepatolenticular foi verificado discreto aumento da concentração protêica do LCR.

Em todos os casos o perfil protêico era de tipo descrito para o LCR normal, isto é, a albumina representava a maior das frações e, entre as globulinas, predominava a fração $\beta$.

$O$ percentual de $\beta$-globulina se achava aumentado em 12 dos casos estudados. $O$ aumento foi verificado de modo mais freqüente entre pacientes com quadro clínico sugestivo de sofrimento encefálico predominante. É assim que foi observado em 3 dos 5 casos nos quais as principais manifestações eram relacionadas a sofrimento rombencefálico e em 7 dos 13 casos com sintomatologia devida a lesões mais rostrais. Dentre os 10 casos de processos degenerativos que comprometiam especialmente a medula espinal só foi observado o aumento de $\beta$-globulina em dois casos (quadro 2).

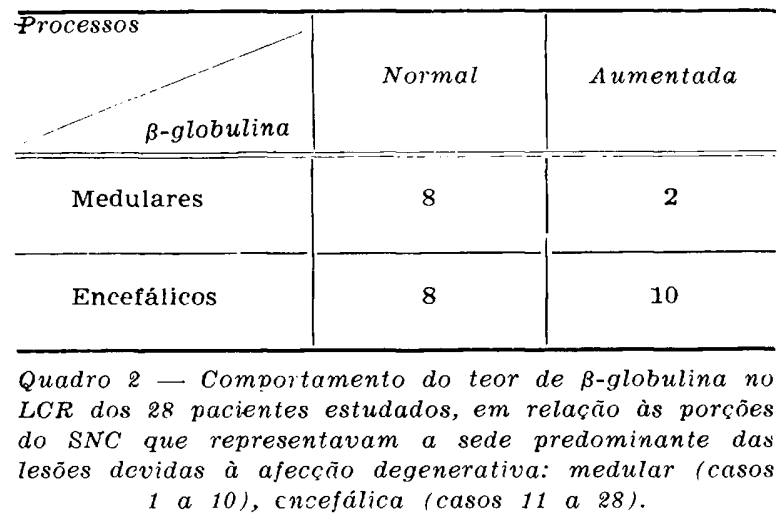

A $\beta$-globulina participa do metabolismo protêico da célula nervosa ${ }^{4}$ Entre os dados favoráveis a êsse modo de ver pode ser lembrado o fato de ser o LCR do espaço subaracnóideo encefálico aquêle que é mais rico em $\beta$-globulina ${ }^{2}$. A favor dêsse ponto de vista está também a ocorrência de aumento do teor de $\beta$-globulina no LCR especialmente em casos de afecçóes degenerativas predominantemente encefálicas, como demonstram os casos estudados.

O aumento da concentração de $\beta$-globulina no LCR parece estar mais relacionado com o processo degenerativo que à etiologia do processo. Os casos apresentados permitem verificar êsse aspecto do problema; o aumento de $\beta$-globulina foi verificado em pacientes com processos degenerativos ligados a diferentes mecanismos etiopatogênicos. Além disso, dentro de um mesmo tipo etiopatogênico, o aumento de $\beta$-globulina não foi observado de modo sistemático $\in \mathrm{m}$ todos os casos. 
Ésse último dado sugere que o aumento de $\beta$-globulina no LCR possa estar relacionado a peculiaridades de cada caso, como a extensão do processo e a ocorrência de surtos de p:ora durante a evolução. Êsses dois fatôres podem ser ilustrados por dois dos pacientes estudados. No caso 15, o quadro clínico era sugestivo de processo degenerativo bastante extenso, em vista da intensidade das manifestações e do comprometimento mesodiencefálico; cêrca de três anos depois, sem que se modificasse a severidade do quadro nesse periodo, nôvo proteinograma do LCR revelou dados semelhantes ao primeiro, isto é, nitido aumento do teor de $\beta$-globulina. No caso 13 , o primeiro exame foi feito em momento em que a evolução da doença assumiu maior gravidade, coincidindo com o aparecimento de manifestaçōes de comprometimento ponto-olivar; cêrca de um ano depois, em fase de evolução mencs severa, nôvo exame já não mostrou a presença de aumento de $\beta$ globulina no LCR.

\section{RESUMO E CONCLUSOES}

Estudo baseado na análise dos dados referentes ao proteinograma do LCR de 28 pacientes com afecções degenerativas do SNC, de diversos tipos. A alteração principal encontrada foi o aumento do teor de $\beta$-globulina, observado em 12 casos.

O aumento dessa globulina ocorreu especialmente em casos com acometimento predominantemente encefálico (10 casos). Não foi observada relação entre o aumento de $\beta$-globulina no LCR e os grupos etiopatogênicos a que pertenciam os casos estudados.

O comprometimento metabólico da célula nervosa nas afecções degenerativas do SNC parece ser o principal responsável pelo aumento de $\beta$-globulina no LCR. Aspectos evolutivos de casos apresentados permitem verificar a relação existente entre a severidade e a extensão do processo degenerativo e o aumento dessa fração protêica no LCR.

\section{SUMMARY}

Protein pattern of the cerebrospinal fluid in degenerative diseases of the central nervous system.

The total protein content and the protein fractions (paper electrophoresis) were determined in the CSF of 28 patients with degenerative diseases of the CNS. The diagnosis and the results obtained are presented in table 1. An increase in the $\beta$-globulin content of the CFS was the main change found. It was observed in 12 cases. The observation confirms the findings of other authors.

The data were discussed and it was shown that the severity of the changes in the metabolism of nerve cells and the extension of the process are more able to explain the increase in the $\beta$-globulin content of the CSF. 
The occurrence of an increase in the $\beta$-globulin content of the CSF was related to the localization and extension of the disease process within the CNS and not to the etiology. The distribution of the cases according to the possible site of the lesion in the CNS shows that the increase in the $\beta$-globulin of the CSF was more frequent when signs of encephalic involvement were patent (table 2).

\section{REFERENCIAS}

1. ESSER, H. - Die Liquoreiweisskorper des Menschen. Zentralblatt f. d. ges. Psychiat., 122:68 (março) 1953. 2. GEINERT, F.; MATIAR, H. - Das elektrophoretische Proteinspektrum in verschiedener Höhe des Liquorsystems. Dtsch. Z. Nervenheilk., 179:111-119, 1959. 3. GREEN, J. B. - Recent advances in the chemistry of the CSF. Arch. Neurol. a. Psychiat., 80:359-374, 1958. 4. MATIAR, H. - Die Erhöhung der $\beta$-Globuline im Liquor. Dtsch. Z. Nervenheilk., 180:191-215, 1960. 5. SPINA-FRANÇA, A. - Eletroforese em papel das proteinas do liquido cefalorraqueano: principais resultados registrados na literatura. Arq. Neuro-Psiquiat., 16: 223-235 (setembro) 1958. 6. SPINA-FRANCA, A. - Eletroforese em papel das proteinas do liquido cefalorraqueano: técnica. Arq. Neuro-Psiquiat., 16:236-242 (setembro) 1958. 7. SPINA-FRANÇA, A. - Eletroforese em papel das proteinas do líquido cefalorraqueano: valôres normais. Arq. Neuro-Psiquiat., 18:19-28 (março) 1960. 8. SPINA-FRANÇA, A.; AMAR, I. - Valôres normais da concentração protêica do liquido cefalorraqueano: variaçóes ligadas ao local de colheita da amostra. Arq. Neuro-Psiquiat., 19:220-225 (setembro) 1961.

Clinica Neurológica - Hospital das Clínicas da Fac. Med. da Univ. de Sũo Paulo Caixa Postal 3/61 - São Paulo, Brasil. 